\title{
EL CLUB CATÓLICO DE MONTEVIDEO: CONFESIONALIDAD, SOCIABILIDAD Y POLÉMICA (1875-1893). UNA BIOGRAFÍA COLECTIVA
}

\author{
POR \\ SUSANA MONREAL ${ }^{1}$ \\ Universidad Católica del Uruguay
}

\begin{abstract}
RESUMEN
Este artículo estudia los intentos de organización de la élite cultural católica montevideana en el último cuarto del siglo XIX, en el contexto de los avances secularizadores y de la progresiva articulación de los universitarios y letrados que tomaban distancia de la Iglesia. El Club Católico nació como centro cultural y espacio de sociabilidad intelectual, que concretó progresivamente su perfil confesional. A la actividad académica, la polémica como constante y el indiscutido perfil católico, se suman dos aspectos de interés: el énfasis en asociar el cristianismo a los fundamentos de la «civilización» y la vinculación de su accionar con la definición del sentimiento nacional.
\end{abstract}

PALABRAS CLAVE: Club Católico; Montevideo; sociabilidad; polémica; civilización; identidad nacional; siglo XIX.

\section{THE CATHOLIC CLUB OF MONTEVIDEO: CONFESSIONALISM, SOCIABILITY AND CONTROVERSY (1875-1893). A COLLECTIVE BIOGRAPHY}

\begin{abstract}
This article examines the organization of the Catholic cultural elite of Montevideo during the last quarter of the 19th Century, in the context of secularization and of the progressive articulation of academics and intellectuals, who were taking distance from the Catholic Church. The Catholic Club was born as a cultural center and as a space of intellectual sociability, which progressively showed its confessional profile. There are two interesting aspects in addition to the academic activity, the controversy as a constant item and the unquestioned Catholic profile: the emphasis on Christianity as the foundations of «civilization» and the connection of its activities with the definition of the national sentiment.
\end{abstract}

KEY WORDS: Catholic Club; Montevideo; sociability; controversy; civilization; national identity; 19th Century.

COMO CITAR ESTE ARTículo / CITATION: Monreal, S. 2017. «El Club Católico de Montevideo: confesionalidad, sociabilidad y polémica (1875-1893). Una biografía colectiva». Hispania Sacra 69, 140: 675-687. doi: 10.3989/hs.2017.042

$\begin{array}{ll}\text { Recibido/Received } & 03-03-2015 \\ \text { Aceptado/Accepted } & 12-03-2015\end{array}$

En Uruguay, durante el último cuarto del siglo xIX, en el contexto de los avances secularizadores y de la progresiva articulación de los universitarios y letrados que tomaban distancia de la Iglesia católica, tuvieron lugar los primeros intentos de organización de la élite cultural católica montevideana, con la fundación del Club Católico de Montevideo en junio de 1875.

Este estudio se inscribe en el campo de la biografía colectiva y se propone realizar un aporte a la historia cultural

\footnotetext{
1 smonreal@ucu.edu.uy / ORCID iD: http://orcid.org/0000-0002 $-2979-4188$
}

y religiosa, poniendo el acento en el proceso de formación de un espacio intelectual y cristiano. Efectivamente, el Club Católico se configuró a través de las contribuciones de generaciones diversas, promovió la definición de perfiles variados y posibilitó el desarrollo de modalidades precisas de sociabilidad cultural. El estudio de este proceso se ha enmarcado entre 1875 , año de fundación del Club Católico de Montevideo, y 1893, año de neto repliegue en las actividades del Club, no necesariamente de la Iglesia católica, y de inicio de una intensa campaña anticlerical, que modificó significativamente la interacción entre católicos y liberales anticlericales. 
La fundación de este primer centro cultural católico en Montevideo coincide con la creación de instituciones semejantes en Europa e Iberoamérica, en el marco del complejo, también polémico, proceso de romanización de la Iglesia católica que se desarrolló a partir de la segunda mitad del siglo XIX. ${ }^{2}$ En tal sentido, en las naciones latinoamericanas, de existencia corta a mediados del siglo $\mathrm{XIX}$, convergieron tres procesos de profundas consecuencias, que se agudizarían en las décadas siguientes, multiplicando las discusiones y los conflictos. Coincidieron, por un lado, la constitución de los estados nacionales y la instauración de las iglesias locales y más vinculadas a la Santa Sede, procesos que no estarían libres de tensiones. Por otra parte, estos procesos serían agentes y consecuencias del proceso secularizador, que intimaba a establecer fronteras, determinar espacios específicos, y redefinir la vinculación entre lo religioso y lo político. ${ }^{3}$

A mediados de 1846, Giovanni Mastai Ferretti, quien había recorrido las capitales del Cono Sur y residido en Montevideo en la década de 1820 , se convirtió en el papa Pío IX. Su pontificado, que duró más de contrastantes 30 años, coincidió con el proceso de centralización romana, que parecía fundarse en cierta aprensión ante la multiplicidad de las iglesias locales y que apoyaba la subordinación del episcopado a la tutela de Roma. Por un lado, el papa y su entorno parecían suponer que de este modo se aseguraría la restauración de la moral católica y se reanimaría el empuje de la Iglesia para enfrentar los desafíos del liberalismo anticristiano. Con el apoyo de las nunciaturas y de la Compañía de Jesús, la romanización marcó por varias décadas la vida de la Iglesia y contó con la adhesión calurosa de las masas católicas, atraídas por la integridad y el carisma de Pío IX. Por otra parte, las autoridades eclesiásticas latinoamericanas transitaron, durante este período, un camino de enfrentamiento a las pretensiones de las gobiernos republicanos de ser herederos del patronato real; el acercamiento a Roma y el apoyo de la Santa Sede fueron decisivos para ganar autonomía ante el Estado. Finalmente la afirmación de este "ultramontanismo» así como las duras condenas a las ideas liberales provenientes del papado provocaron el rechazo creciente de grupos intelectuales, de dirigentes políticos y de todos aquellos que interpretaban las posiciones vaticana y de las iglesias locales como un anuncio de alejamiento -incluso de ruptura- con la modernidad. En el caso uruguayo, el carácter tardío de la evangelización del territorio así como de la instalación de autoridades eclesiásticas, con cierto grado de autonomía, otorgaron al proceso características propias.

En este artículo, luego de exponer el proceso de fundación del Club Católico vamos a detenernos en los objetivos de esta sociedad. Presentaremos luego a los protagonistas del proceso, sus perfiles diversos y el carácter de la sociedad como centro de numerosas polémicas, para analizar finalmente dos constantes en el discurso que se desarrolló en el seno del Club: la asociación de los conceptos de cristianismo y civilización, y la vinculación de la identidad católica y la identidad nacional.

2 Sobre el controvertido concepto de romanización: De Roux 2014; Di Stefano 2010; Santirocchi 2010; Clark 2003, en Clark y Kaiser: 11-46.

3 Di Stefano 2010: 220-222.

\section{LA FUNDACIÓN DEL CLUB Y SU CONTEXTO}

En Uruguay, desde fines de la década de 1870, cambios diversos se asociaron para propiciar el surgimiento de una sociedad nueva, sucesora de la sociedad oriental ${ }^{4}$, que se consolidaría a comienzos del siglo Xx. Sucesos políticos complejos, crecimiento económico, renovación social por los movimientos migratorios y cambios culturales de significación sostendrían este proceso. El desarrollo de diversos tipos de sociabilidad, algunos de marcado carácter cultural, sería -como en las demás ciudades de la regiónotro rasgo de la época. ${ }^{5}$ Clubes filosóficos y literarios, sociedades educativas y religiosas, logias masónicas, asociaciones de librepensadores se multiplicaron.

En el campo cultural, Montevideo se convirtió en el escenario, al decir de Arturo Ardao, de «un cruce polémico de ideologías, sin precedentes en la historia». ${ }^{6}$ Corrientes de origen religioso -el catolicismo y el protestantismo metodista- y corrientes de carácter filosófico -el racionalismo espiritualista y el positivismo incipiente- fueron los protagonistas de un período fermental, en el que la juventud universitaria jugaría un papel destacado.

En este contexto, en un reducido ambiente universitario, la sociabilidad se manifestó a través de la fundación de clubes o sociedades culturales. ${ }^{7}$ Este movimiento asociativo comenzó, en 1868, con la fundación del Club Universitario. Con el apoyo de algunos profesores y en particular de Plácido Ellauri ${ }^{8}$, portavoz del espiritualismo ecléctico de Victor Cousin, un grupo de estudiantes se reunió en este centro, para continuar fuera de las aulas las exposiciones y debates de carácter filosófico, histórico, religioso y político. Ese mismo año se fundó la Sociedad de Amigos de la Educación Popular, impulsada por José Pedro Varela y orientada a la promoción de los principios de la educación primaria gratuita y obligatoria. Entre junio de 1872 y junio de 1873, el Club Universitario convivió con el Club Racionalista, que nació como un desprendimiento racionalista del primero. En el seno del Club Racionalista se redactaría la Profesión de Fe Racionalista, de julio de 1872, que representó el distanciamiento oficial de un grupo de jóvenes universitarios de la Iglesia católica.

El movimiento adquirió impulso entre 1874 y 1876 . Se fundaron entonces una decena de sociedades, con perfiles variados, a menudo de vida efímera: el Club Joven América, la Sociedad de Estudios Preparatorios, el Club Fraternidad,

4 El actual territorio de la República Oriental del Uruguay, o Uruguay, recibió el nombre de Banda oriental -del río Uruguay-durante el período colonial, y el de Provincia oriental, durante el período revolucionario, utilizándose el gentilicio «oriental» para los nacidos en esta tierra, incluso en nuestros días.

Sobre sociabilidad cultural: Bruno 2014 y 2009; Molina 2011; Sábato 2008.

6 Ardao 1971: 93.

Sobre el origen y la evolución de las sociedades culturales: Acevedo 1934, t. 4: 124-126; Ardao 1962: 64-77; Pollero 1988.

8 Plácido Ellauri (Buenos Aires, 1815-Montevideo, 1893) Fue doctor en Derecho, magistrado, profesor de filosofía en la Universidad (18521877 y 1883-1888), director del Instituto de Instrucción Pública (1869) y rector de la Universidad Mayor (1871-1873 y 1875-1876). Durante su rectorado, se instalaron las cátedras de Física e Historia Natural, precursoras de la fundación de la Facultad de Medicina. Plácido Ellauri difundió el espiritualismo ecléctico de Cousin; sus discípulos lo veneraron y adoptaron las ideas que enseñaba, aunque las abandonaran más tarde. 
la Sociedad Filo-Histórica, la Sociedad de Ciencias Naturales, la Sociedad Universitaria, el Club Literario Platense. La más estable, en el campo liberal, sería el Ateneo del Uruguay, fundado en setiembre de 1877, a partir de la fusión de cuatro clubes preexistentes -la Sociedad Filo-Histórica, la Sociedad de Ciencias Naturales, el Club Literario Platense y el Club Universitario-. La nueva institución nucleó a los librepensadores montevideanos y en su seno se vivieron las tensiones provenientes de las filiaciones filosóficas opuestas, espiritualista o positivista.

En este período, seis estudiantes católicos crearon su propia asociación, con el apoyo de Jacinto Vera, vicario apostólico desde 1859, y bajo cuyo liderazgo la naciente y débil Iglesia uruguaya había avanzado en definición doctrinal y en organización. El 25 de marzo de 1874 tuvo lugar la fundación de la Sociedad Filosófica-ReligiosoLiteraria, con el objetivo de «estudiar y tratar todas aquellas cuestiones que por su importancia propendan al desarrollo moral e intelectual del individuo». En esta propuesta, algo vaga, no se percibe una alusión definida a la inspiración cristiana católica de la fundación. Sus promotores fueron Román Barlén, Ramón López Lomba, Horacio Tabares, Justo José Caraballo, Horacio Marella y Antonio Sánchez. ${ }^{9}$

Según la versión de Antonio M. a Barbieri, basada en el testimonio de Román Barlén, el fraile capuchino Vito Ángel de Gioia habría sido el primer impulsor de esta institución católica. El citado Barlén y Ramón López Lomba «concibieron el propósito de tutelar la fe entre sus compañeros reuniéndolos para fortificarse mutuamente en la piedad mediante el ejemplo y el estudio colectivo de la Doctrina Católica» y comunicaron su proyecto al padre Gioia, quien «para poner un buen cimiento a la obra proyectada dispuso que hicieran los dos jóvenes ocho días de ejercicios espirituales bajo su dirección». Sigue Barbieri: «Al tercer día de los ejercicios (...) se nos agregó un compañero, el agrimensor Horacio Tabares, joven recién convertido; cuando terminamos los ejercicios, se nos adhirió Justo J. Caraballo, y más tarde Antonio Sánchez, Horacio Marella y otros». Según la misma fuente, la primera Comisión fue integrada por el P. Vito Angel de Gioia, como director; Antonio Sánchez, presidente; Horacio Tabares, vicepresidente; Justo J. Caraballo, secretario. ${ }^{10}$ En la versión del Cardenal Barbieri -y de Ramón Barlén- el padre Vito nunca asistió a las reuniones de la sociedad, por realizarse en la noche y prolongarse hasta tarde. Por otra parte, la asociación no tuvo, en su primera etapa, un domicilio fijo. Nunca se reunió en el convento capuchino de San Antonio, «por estar éste muy fuera de mano para los que vivían en el Centro». En estas circunstancias, el vicario Vera les habría ofrecido su propio domicilio para realizar las reuniones. ${ }^{11}$

Este puñado de jóvenes, todos menores de veinte años, se reunió en forma regular durante dos meses en 1874 -entre el 3 de mayo y el 18 de julio- y menos de un mes en 1875 -entre el 16 de mayo y el 6 de junio. Desarrollaron

9 Acta 25 de marzo de 1874, Archivo Club Católico de Montevideo (ACCM), Sociedad Filosófica-Religioso-Literaria, Libro de Actas, 18741875. Ese mismo día se eligió la Comisión Directiva de la Sociedad: Antonio Sánchez (presidente), Horacio Tabares (vicepresidente) y Justo J. Caraballo (secretario).

10 Barbieri 1933: 69.

11 Ibídem: 70. actividades que manifestaban el deseo de formarse, la efervescencia propia de la edad y el carácter asistemático de su sed de saber. Con cierto desorden, se sucedieron, en este período, la lectura de artículos de revistas o de libros sobre temas históricos, filosóficos o religiosos y la exposición de tesis de temas muy diversos. Citamos, a modo de ejemplo, las ocho tesis leídas en 1874: "Historia de las Guerras Púnicas» por Justo José Caraballo; «Legislación de Atenas» por Juan F. Loriente; "Indiferencia de la sociedad hacia los criminales y desgraciados» por Horacio Tabares; "La insuficiencia de la educación generalmente dada pues sólo ilustra la inteligencia sin cuidar la ilustración del corazón» por Ramón López Lomba; "Pruebas de la existencia de Dios» por Gabriel Sienra; "Consuelos que presta la religión en las amarguras de la vida» por José Mazarino.

A los seis fundadores pronto se unieron nuevos miembros y la sociedad contaba con diecinueve integrantes cuando se decidió su reestructura. En 1875 se integraron algunos de los socios que serían apoyos constantes del futuro Club Católico, como Antonio J. Rius, Vicente Ponce de León, Hipólito Gallinal (h) y Jacinto Casaravilla. Eran todos cercanos al Pbro. Mariano Soler, llegado de Roma en 1874, quien parecía haberse propuesto afirmar el perfil católico de la asociación para abordar su reestructura más tarde. En efecto, por iniciativa de Soler y de sus jóvenes seguidores se habría resuelto la reforma de la Sociedad y su transformación en Club Católico de Montevideo, un centro claramente vinculado a la jerarquía y asociado al proyecto de preparar la fundación de un "Colegio Superior Católico», núcleo inicial de una Universidad Libre o Católica. ${ }^{12}$

La sesión del 6 de junio de 1875 fue decisiva para el futuro de la sociedad católica. «En esa reunión se decidió formar o mejor dicho reformar esta Sociedad dándole mayor amplitud y otras bases como medio de preparar la fundación del Colegio Superior Católico para principios del año entrante». Con ese propósito se eligió «una Comisión Directiva para la fundación o reforma de la Sociedad Católica de jóvenes», integrada por Jacinto Vera, Joaquín Requena, Nicolás Zoa Fernández, Mariano Soler, Ricardo Isasa, Augusto Serralta y Ramón López Lomba. ${ }^{13}$ Por otra parte, por primera vez aparecían ligados la sociedad, que pasaría a llamarse Club Católico, y el proyecto de creación de un instituto católico de estudios superiores.

12 A la llegada a Montevideo de los restos mortales de Mariano Soler, en octubre de 1908, Vicente Ponce de León, designado orador por el Club Católico, expresó: "Señores: El 20 de junio de 1875, una sociedad formada por jóvenes, casi niños, que se distinguía con el nombre de 'Sociedad Filosófica y Literaria' acordaba, por unanimidad, recibir como socio activo y aceptar como su director, a un sacerdote recién llegado de Roma, doctor en ambos derechos y que traía, de la Ciudad de los papas, el prestigio de un premio ganado en un concurso de 500 escolares. La misma noche la Sociedad indicada resolvía, a propuesta del nuevo socio, cambiar su nombre y llamarse desde entonces 'Club Católico de Montevideo'». El Bien, Montevideo, 8 de octubre de 1908. Archivo Curia Eclesiástica de Montevideo (ACM) Recortes de prensa referentes a la muerte de Mariano Soler, 1908, cajón 309. Ponce de León hace coincidir el día 20 de junio el ingreso de Soler a la Sociedad, la propuesta de reforma de la misma y la erección del Club Católico, lo que no corresponde a los hechos según consta en actas. Los recuerdos de Ponce de León se habrían vuelto borrosos o las exigencias de la retórica no permitían mayores detalles.

${ }_{13}$ Acta 6 de junio de 1875, ACCM, Sociedad Filosófica-ReligiosoLiteraria, Libro de Actas, 1874-1875. 


\section{LOS OBJETIVOS DEL CENTRO CATÓLICO}

Desde su creación el Club Católico se habría propuesto jugar dos roles, que ganaron definición en el proceso fundacional. En primer lugar, se trataba de un centro cultural, un espacio de sociabilidad intelectual, que se proponía nutrir «el desarrollo moral e intelectual del individuo». Por otra parte, el Club fue concretando su perfil confesional y se erigió como espacio de fortalecimiento de una identidad filosófica y religiosa precisas, como centro «en donde la juventud católica se ilustra con el estudio y la discusión y se aúna para la lucha que está llamada a sostener contra la propaganda del error y la impiedad». ${ }^{14}$ Era evidente la preocupación de la Iglesia por sostener la identidad católica de los jóvenes que, de acuerdo a las fuentes confesionales, una vez que ingresaban a la universidad se volvían «indiferentes o incrédulos».

El domingo 13 de junio de 1875, en la sesión de enlace entre la Sociedad que desaparecía y el Club Católico próximo a nacer, Horacio Tabares pronunció un elocuente discurso. Expuso entonces las dos motivaciones de la reestructura de la sociedad: la necesidad de centrar la nueva sociedad en el estudio y la formación religiosa «en un siglo de discusión, ignorancia y superficialidad», y el proyecto de fundar un Colegio Católico de Estudios Superiores que salvaguardara la fe católica de los jóvenes y evitara el divorcio entre ciencia y fe que se vivía en la Universidad. ${ }^{15}$ Una semana más tarde, el 20 de junio, se concretó la fundación del Club Católico de Montevideo, en la casa del vicario Vera. Se aprobaron los Estatutos de la nueva asociación y se comunicó la designación realizada por Vera, como lo establecían los Estatutos, de los directores del Club, los Pbros. Mariano Soler y Ricardo Isasa. ${ }^{16}$

Cuatro días después tuvo lugar el acto de inauguración del Club, y Mariano Soler ${ }^{17}$ pronunció un discurso de tono combativo, propio de su temperamento y de las circunstancias de confrontación ideológica que se vivía entre las sociedades culturales. Desde julio de 1872, tras la publicación de la Profesión de Fe Racionalista, respaldada por veinticinco estudiantes de la Universidad Mayor, los enfrentamientos habían ganado vehemencia. La siguieron una Carta Pastoral condenatoria de Jacinto Vera y una Contra pastoral, apoyada por una treintena de firmantes. ${ }^{18}$ Dos años más tarde, se plantearon nuevas rispideces cuando, en una nueva Carta Pastoral, Mons. Vera manifestó el rechazo católico a la prédica laicista de la Sociedad de

\footnotetext{
14 «Inauguración del Club Católico», El Mensajero del Pueblo (EMP), Montevideo, 27 de junio de 1875.

15 Acta 13 de junio de 1875, ACCM, Sociedad Filosófica-ReligiosoLiteraria, Libro de Actas, 1874-1875 y Club Católico de Montevideo. Libro de Actas no 1 . 1875-1883.

16 Acta 20 de junio de 1875. ACCM, Club Católico de Montevideo. Libro de Actas no 1. 1875-1883.

17 Mariano Soler (1846-1908) nacido en una familia humilde del pueblo de San Carlos (Maldonado), fue ordenado sacerdote en 1872 , en Roma. Doctor en teología y en derecho canónico por la Universidad Gregoriana, fue fundador del Club Católico de Montevideo (1875), de la Universidad Libre o Católica (1878) y del Círculo Católico de Obreros de Montevideo (1885). Fue el segundo fundador del Colegio Pío Latinoamericano de Roma, tercer obispo de Montevideo (1890-1897) y primer arzobispo de Montevideo (1897-1908)

18 Ver Ardao 1962: 235 ss.; Paris de Oddone 1958: 120 ss.; Villegas 1989.
}

Amigos de la Educación Popular. ${ }^{19}$ La polémica alcanzó la prensa, unos meses más tarde, con la oposición de los estudiantes de Derecho Canónico de la Universidad Mayor a ser examinados por el Dr. Ricardo Isasa. ${ }^{20}$

Volviendo al discurso de Soler, en el mismo se destacan dos ideas, que revelaban el espíritu fundacional del Club Católico: la importancia de los jóvenes en las empresas de orden religioso, social y cultural, y las relaciones entre racionalismo y libertad de conciencia. En relación con el primer punto, Soler señalaba:

«Hay un hecho en la Historia, grande para la filosofía y grande para la civilización, el hecho de haber sido siempre la juventud la esperanza más bella de la religión y de la patria. Cuando en determinadas épocas se hizo necesaria la regeneración religiosa y la regeneración social, cuando genios inmortales soñaron en la felicidad de los pueblos, la Iglesia y el Estado pusieron sus ojos en las generaciones nacientes para realizar esas empresas gigantescas y esas grandes transformaciones sociales de que nos da cuenta la historia en páginas de oro. Por eso fue cuidado predilecto del catolicismo levantar al lado de cada templo una escuela y la Universidad en el seno de cada metrópoli». ${ }^{21}$

En la segunda parte del discurso, Soler analizaba los fundamentos del racionalismo y sus relaciones con «la libertad de conciencia», que definía como adhesión libre y generosa a la verdad revelada, considerando dicha verdad revelada como liberadora del error y de las imperfecciones humanas.

«Así lo habéis pensado también vosotros, jóvenes católicos, y determinasteis formar un centro de reunión donde, ilustrando vuestras creencias con el estudio de las verdades más importantes de las ciencias filosóficas en sus relaciones con la Religión, podáis defender científicamente la libertad de vuestra conciencia católica y los dogmas augustos y doctrinas regeneradoras del catolicismo». ${ }^{22}$

El 20 de junio fue aprobado el Reglamento del Club Católico, que exponía, en su primer artículo, el objeto de la asociación y las medidas para alcanzarlo. Se lee en el Artículo 1ㅇ:

«El objeto primordial de esta Asociación es formar un centro científico-religioso en donde los católicos y sobre todo la juventud se ilustra y continúa en sus creencias por medio de la discusión y defensa de las verdades más trascendentales de las ciencias, principalmente filosóficas en sus relaciones con los dogmas y doctrinas del catolicismo; tender a la propaganda de esas mismas doctrinas eminentemente progresistas y civilizadoras por medio de la prensa periódica, la institución de establecimientos de enseñanza, bibliotecas públicas,

\footnotetext{
19 EMP, Montevideo, 19 de febrero de 1874

20 «La enseñanza universitaria (...) tiene un carácter independiente y mal podría obedeciendo los fines de su institución, auxiliar con su esfuerzo y su prestigio la propagación del catolicismo ni de ninguna otra religión que se creyera con más títulos al avasallamiento de los hombres». "Cuatro palabras al doctor Isasa», La Voz de la Juventud, Montevideo, 18 de julio de 1875. La Voz de la Juventud era el portavoz de un sector de los estudiantes montevideanos.

${ }^{21} E M P$, Montevideo, 1을 de julio de 1875. El discurso fue recopilado más tarde en Ensayos de una pluma, obra de la que citamos. Soler 1877: 5 y 6.

22 Ibídem: 14.
} 
librerías; y a que los católicos se animen mutuamente en la defensa de sus derechos sagrados, y a la práctica y pública manifestación de sus creencias. En una palabra, el progreso y civilización bajo todos sus aspectos, pero basados en el catolicismo o que no estén en oposición con el mismo». ${ }^{23}$

En la misma línea de pensamiento, en los Informes de las visitas ad limina de Mons. Inocencio M. $\underline{a}$ Yéregui, de 1888, y de Mons. Mariano Soler, de 1896, se aludía al papel del Club Católico en la cultura del Uruguay, en proceso de modernización y disciplinamiento. ${ }^{24}$

En el informe de Yéregui, diez años después de la fundación del Club, el rol académico y el rol social recreativo aparecían en un mismo nivel:

«El 'Club Católico' se fundó con el fin de congregar todo el elemento no obrero, para aunar en las luchas de la fe a todos aquellos que conservaban los sanos principios de la doctrina católica y conservarlos en esos principios y atraer a los indiferentes y aún convertir a los rebeldes. Al efecto, esta institución comprendió todos sus trabajos bajo dos puntos de vista: instruir y recrear. Instruir a los hijos de los socios y aún a los que no pertenecían a las familias de éstos, y para ello fundó la universidad católica (...) y además se han dado conferencias públicas, siendo libre la discusión, para instruir a los creyentes y convencer a los impíos; el trabajo no ha sido estéril.

Además (...) el Club Católico se ha constituido en centro de honesto pasatiempo para sus socios, a fin de separarlos de las diversiones y compañías perniciosas (...). Todo esto ha hecho que el Club Católico sea reputado por la primera y más interesante corporación de Montevideo (...)». ${ }^{25}$

En 1896, en el informe de Soler se aludía al papel cumplido por el Club Católico y por el Círculo Católico de Obreros para el "progreso espiritual» del país, en sectores sociales bien diferentes:

«Ambas instituciones llevan una marcha próspera y cuentan con crecido número de asociados; tienen su centro de reunión; celebran frecuentes asambleas y fiestas, y especialmente el Club Católico, con sus veladas y certámenes y conferencias, es el centro donde se congrega todo lo más culto y distinguido de nuestra sociedad $»{ }^{26}$

Parece claro que el Club Católico nació, en 1875, como espacio de promoción de la fe cristiana y de la cultura católica. En las décadas siguientes, a las actividades académicas se sumarían las actividades sociales y recreativas, por lo que el Club se consolidaría como un espacio de custodia de la fe y de la cultura católicas, y como ámbito de encuentro de

23 Club Católico de Montevideo. 1875. Estatutos del Club Católico Central de Montevideo inaugurado el 24 de junio de 1875: 3 y 4. Montevideo: Tipografía de El Mensajero del Pueblo.

24 En 1990 José Pedro Barrán publicó los dos tomos de la Historia de la sensibilidad en el Uruguay. El primero de ellos, sobre el período de 1800 a 1860, fue titulado La cultura «bárbara». El segundo tomo se titula El disciplinamiento (1860-1920) y se refiere al período de modernización económica y social en el Cono Sur. Estas obras se inspiran en el clásico trabajo de Michel Foucault, Surveiller et punir: Naissance de la prison de 1975.

${ }^{25}$ Informe visita ad limina Mons. Inocencio M. $\underline{a}$ Yéregui, Montevideo, 5 de julio de 1888, f. 53. ACM, Serie Obispado, Mons. Inocencio Yéregui, Carpeta 1888.

${ }^{26}$ Informe visita ad limina Mons. Mariano Soler, Montevideo, 1896, f. 82. ACM, Serie Obispado, Mons. Mariano Soler, Carpeta 1885-1896. la burguesía católica montevideana. En síntesis, desde su fundación, el Club cumplió funciones de centro académico católico, centro social y cultural, centro de resistencia y centro impulsor de proyectos. ${ }^{27}$ En 1900, Juan Zorrilla de San Martín definiría al Club Católico como «casa madre de todas las instituciones laicas católicas». ${ }^{28}$

\section{LOS PROTAGONISTAS Y SUS RELACIONES}

A partir de 1875, y durante las primeras décadas de vida del Club, se conformó una trama integrada por personas que compartían intereses intelectuales, la fe católica y un fuerte compromiso con el programa social y cultural de la Iglesia. Es el momento de detenerse en los protagonistas que dieron vida a este centro.

En primer lugar, en su versión definitiva, el Club Católico representó una iniciativa intergeneracional. Y no debería ponerse el acento en la figura del vicario Jacinto Vera, quien apoyó el proceso de fundación pero tuvo muy limitada participación en el mismo. Su estilo personal y su perfil orientado a las tareas pastorales, especialmente a las misiones rurales, no concordaban con las actividades del Club. De todos modos, es evidente que desde la integración de la primera Comisión Directiva, se reunieron personas de edad y origen diversos: el vicario Jacinto Vera ya sexagenario; Joaquín Requena y Nicolás Zoa Fernández, dos representantes adultos del laicado católico; Mariano Soler y Ricardo Isasa, dos jóvenes sacerdotes en sus 30 años, doctorados en Roma, y Augusto Serralta y Ramón López Lomba, dos veinteañeros. ${ }^{29}$ También resulta evidente el protagonismo de los primeros sacerdotes uruguayos formados en Roma y las primeras generaciones de egresados de los colegios congregacionales.

En cuanto a Soler e Isasa, estrechamente ligados a la fundación de la asociación, su vinculación con la misma tuvo suerte variada. Habían nacido en 1846, Soler, y en 1847, Isasa, en el seno de familias católicas, y habían afirmado su vocación sacerdotal junto a Jacinto Vera, quien promovió la continuación de sus estudios con los padres de la Compañía de Jesús, primero en el Colegio de la Inmaculada Concepción, en Santa Fe, y más tarde, en Roma, en el Colegio Pío Latinoamericano y la Universidad Gregoriana. Ambos fueron ordenados en Roma, el 20 de diciembre de 1872, obtuvieron el doctorado por la Universidad Gregoriana y regresaron juntos a Uruguay, en $1874 .{ }^{30}$ Su designación como directores del Club, el 20 de junio de 1875, evidenciaba una política definida de supervisión de las iniciativas y actividades de los jóvenes estudiantes, encomendada a dos sacerdotes formados en Roma. Soler e Isasa compartieron la dirección

\section{Monreal 1991.}

28 «Discurso pronunciado en la velada celebrada en el Club Católico de Montevideo, para celebrar el XXV aniversario de su fundación», en Zorrilla de San Martín 1965: 75.

${ }_{29}$ Acta 6 de junio de 1875, ACCM, Sociedad Filosófica-ReligiosoLiteraria, Libro de Actas, 1874-1875. Jacinto Vera (1813-1881), Joaquín Requena (1808-1901), Nicolás Zoa Fernández (casado en 1850 con Catherine O'Neill), Mariano Soler (1846-1908), Ricardo Isasa (1847-1929), Augusto Serralta (1856-?), Ramón López Lomba (1856-?)

30 Ambos compartieron su período de formación, su ordenación y su regreso a Uruguay con el Pbro. Norberto Betancur, sobrino segundo de Jacinto Vera. Betancur se dedicó a sus tareas como párroco y participó muy poco en las actividades del Club Católico. 
del Club durante casi un año, sin embargo Soler pronto se trasformó en el orientador de la sociedad, por su prestigio intelectual, su perfil conciliador y su confianza en la acción de los jóvenes laicos.

Ricardo Isasa ${ }^{31}$ tenía un estilo más severo, a menudo intransigente, que no favorecería las mejores relaciones con los socios. A los enfrentamientos con los estudiantes de la Universidad Mayor, que Isasa consideraba el arsenal «de todos los errores y todas las herejías», siguieron tensiones en la asociación católica y algunos desacuerdos con Soler. En marzo de 1876, actuando Isasa como director del Club y en ocasión de un acalorado debate que siguió a una tesis expuesta por Soler sobre «Posibilidad y necesidad de la Revelación», Soler y Ramón López Lomba -en apoyo del expositor- se enfrentaron a Prudencio Vázquez y Vega y Manuel B. Otero -visitantes racionalistas, defensores de los principios de la religión natural. La prohibición de los aplausos por parte de Isasa, por considerarlos excesivos, motivó las protestas de algunos socios del Club y una posterior reforma del Reglamento, que limitaría las atribuciones del director. En desacuerdo con la reforma, Isasa actuó por última vez como director el 21 de mayo de 1876 y solo volvió al Club Católico en muy contadas ocasiones. ${ }^{32}$ En polémica con $\mathrm{La}$ Voz de la Juventud, Isasa había escrito, en julio de 1875: "La verdad es por naturaleza exclusivista e intransigente y el que la posee debe participar de sus propiedades». ${ }^{33}$

Mariano Soler había recibido la misma formación que Isasa y tenía también carácter dominante, sin embargo manifestaba más empatía con los jóvenes y mayor percepción de las características de la sociedad uruguaya y de los cambios que se estaban desarrollando. En 1876 actuó con tacto en ocasión del referido conflicto entre Isasa y algunos jóvenes. Promovió entonces la participación de los socios en la gestión del Club, mediante la creación de nuevos cargos directivos para "estimular a los jóvenes que fuesen nombrados». ${ }^{34}$ Volvió a cumplir el rol de conciliador, en julio y agosto de 1883, al discutirse un homenaje a Francisco Bauzá y su admisión como socio honorario del Club. ${ }^{35}$ En 1884, Soler intervino nuevamente en favor de los «vacilantes», reticentes a demostraciones públicas y corporativas de fe, para que se suavizaran los términos del Reglamento del Club, que obligaban a los socios a cumplir «en corporación» el precepto pascual. No tuvo éxito, y como en otras ocasiones, se replegó ante la decisión de los laicos. ${ }^{36}$ En los hechos, Soler e Isasa terminaron desempeñando roles diversos en el Club. En teoría, Mons. Vera seguramente

31 Ricardo Isasa (1846-1929) Ordenado sacerdote en Roma en 1872, a su regreso en Montevideo desempeñó diversas funciones pastorales. En 1891 fue designado obispo auxiliar de Montevideo y, en 1897, obispo de la recién creada diócesis de Salto, si bien el Estado uruguayo no permitió que tomara posesión de la misma. A la muerte de Mariano Soler, imposibilitada la Santa Sede de nombrar sucesor por el conflicto con el gobierno, Isasa se desempeñó como administrador de la Iglesia uruguaya, hasta 1918.

32 Actas 26 de marzo, 6, 27 y 30 de abril, 11, 14 y 21 de mayo de 1876. ACCM, Club Católico de Montevideo. Libro de Actas no 1. 1875-1883.

33 Citado en Paris de Oddone 1958: 129-130.

34 Acta 11 de mayo de 1876. ACCM, Club Católico de Montevideo. Libro de Actas no 1. 1875-1883.

35 Actas 26 de julio, 1 y 3 de agosto de 1883. ACCM, Club Católico de Montevideo. Asambleas Ordinarias y Extraordinarias. 1883-1923.

${ }^{36}$ Actas 20 y 22 de febrero de 1884. Ibídem. confiaba en que sus dos discípulos encauzarían la obra y orientarían el discurso de la sociedad en la línea del «Nuevo Catolicismo», al decir de Christopher Clark, «más uniforme, más centralizado y más romano». ${ }^{37}$

Como sociedad académica, el Club Católico cumplió el rol de centro de formación y de entrenamiento de jóvenes laicos. La mayoría de los socios del Club había nacido entre 1854 y 1866, superada la Guerra Grande, y habían madurado en un país de cambios lentos, fuerte influjo brasileño en la economía y progresiva llegada de inmigrantes. Muchos provenían de los colegios católicos congregacionales y estaban iniciando los estudios superiores al integrarse al Club. Entre los fundadores y muy activos primeros socios del Club Católico se contaron varios ex-alumnos de los padres betharramitas ${ }^{38}$ : Antonio J. Rius, Jacinto Casaravilla, los hermanos Jacinto D., José D. y Nicolás D. Durán, y Héctor Pareja. ${ }^{39}$ En el Colegio Pío de Villa Colón ${ }^{40}$, de los padres salesianos, habían estudiado Eduardo y Alejo Arocena, Rafael Fragueiro, José García Wich, Luis Pedro Lenguas y Ludovico Migone. ${ }^{41}$ Entre 1874 y 1876, ingresaron al Club los primeros estudiantes del Liceo de Estudios Universitarios; algunos habían realizado sus estudios primarios en los colegios antes nombrados: Eugenio Zoa O’Neill, Jacinto Casaravilla, Vicente Ponce de León, Jacinto de León, José D. Durán, Antonio J. Rius, Hipólito Gallinal (h), Rafael Ardito, Javier Gurruchaga, Luis Gómez. Otros alumnos del Liceo ingresaron al Club más tarde: Marcelino Izcua Barbat, Enrique Platero, Miguel V. Martínez, Estanislao e Isaías Soler -hermanos de Mariano Soler- y Carlos Rusiñol. ${ }^{42}$ También llegarían socios formados en institutos católicos del exterior: Juan Zorrilla de San Martín y Luis Piñeyro del Campo se formaron con los jesuitas en el Colegio de la Inmaculada Concepción de Santa Fe; Jacinto de León estudió algunos años en el colegio de San José de los padres bayoneses en Buenos Aires; José Máximo Carafí lo había hecho en el Instituto Jaime Balmes de Barcelona. ${ }^{43}$

Precisamente el desarrollo y los efectos de los estudios universitarios fueron elementos significativos para la permanencia o el alejamiento de algunos socios. Entre los que se distanciaron del Club se cuentan Ramón López Lomba, Saturnino Camp y Marcelino Izcua Barbat, y Jacinto de León

37 Clark 2003 en Clark y Kaiser: 11.

38 En noviembre de 1856 había llegado a Buenos Aires el primer grupo de religiosos de la Congregación del Sagrado Corazón de Jesús de Betharram, llamados padres bayoneses en la capital argentina y padres vascos en Montevideo. Desde 1859 los Vascos acompañaron a Jacinto Vera en las misiones rurales y el vicario realizó gestiones a favor de su instalación en Uruguay. En 1861 dos religiosos se establecieron en Montevideo, dedicándose a la atención de la comunidad vasca, a la predicación y a la capellanía del Hospital de Caridad. En 1867 fundaron el colegio de la Inmaculada Concepción. Monreal 2005: 72-74.

39 Testimonio de Jacinto D. Durán en: Sociedad de Ex alumnos del Colegio-Liceo de la Inmaculada Concepción. 1940. Breve historia del Colegio: 10. Montevideo: s. e.

40 Los padres salesianos llegaron a Uruguay en diciembre de 1876, por iniciativa del P. Juan Cagliero, misionero en la Patagonia. Liderados por el P. Luis Lasagna, los salesianos fundaron el Colegio Pío de Villa Colón, en febrero de 1877. Una historia nos impulsa. 125 años de presencia salesiana en Uruguay. 2001. Montevideo: El País.

41 EMP, Montevideo, 3 de junio de 1877.

42 EMP, Montevideo, 30 de diciembre de 1877.

43 Zorrilla de San Martín 1970: 20-22; Piñeyro Gutiérrez 2009: 32-33; Wilson 1992: 76; Pou Ferrari y Mañé Garzón 2013: 15-19. 
una década más tarde. El caso de López Lomba reviste especial interés, por haber había sido uno de los seis fundadores de la Sociedad inicial y por haber ocupado cargos relevantes en la Junta Directiva del Club hasta el día de su renuncia. Desde 1875, López Lomba había participado en los debates en defensa del catolicismo en el Club Universitario y en el Ateneo de Montevideo, y había disertado con frecuencia en la sociedad católica. Los repetidos desencuentros con Ricardo Isasa, la influencia del ambiente universitario racionalista y tal vez la muerte de Horacio Tabares, primer presidente del Club y su gran amigo, habrían influido en su ánimo y lo conducirían a la dimisión y al alejamiento de la fe. A los dos meses de haber sido electo presidente del Club Católico, el 20 de mayo de 1877, López Lomba renunció como presidente y como socio. ${ }^{44}$ En octubre de ese mismo año fue designado inspector de Instrucción Primaria en el departamento de Paysandú y, en 1879, ingresó a la masonería también en Paysandú. ${ }^{45}$ Se graduó como doctor en Derecho en 1883 y en 1888 impulsó la fundación de la Liga Patriótica de Enseñanza, organización laica que se definía como «un centro permanente de propaganda y de acción $\aleph^{46}$, se proclamaba "ajena a todo espíritu de intolerancia» y adoptó «por divisa el aforismo evangélico de la caridad de Jesús para con los niños. Sinite parvulos venire ad me: será nuestro lema». ${ }^{47}$ López Lomba culminó su carrera como cónsul general del Uruguay en Francia, durante el gobierno reformista de José Batlle y Ordóñez. Saturnino Camp se alejó del Club con López Lomba y, en 1881, consagraría su tesis doctoral en Derecho al tema de la enseñanza obligatoria. ${ }^{48}$ Izcua Barbat renunció en marzo de 1878 y pronto se vinculó a los círculos racionalistas, más precisamente con la Sección de Filosofía del Ateneo y con la Sección de Ciencias Sociales de la Sociedad Universitaria. Como López Lomba, Izcua Barbat integró la Liga Patriótica de Enseñanza y la Unión Liberal. ${ }^{49}$

Entre los primeros miembros del Club, se detecta también un grupo de socios siempre cercanos a la sociedad y cuyo apoyo fue incondicional durante varias décadas: Jacinto Casaravilla, Eugenio Zoa O’Neill, Juan M. O’Neill, Antonio J. Rius, Vicente Ponce de León, Hipólito Gallinal (h). Constructores silenciosos, ocuparon cargos de responsabilidad en la sociedad sin descuidar su trabajo en el comercio, el foro, la prensa o la vida política. Todos

44 La renuncia de López Lomba causó conmoción en el Club. Acta 20 de mayo de 1877. ACCM, Club Católico de Montevideo. Libro de Actas no 1. 1875-1883. En 1935, en un artículo publicado en el diario El Día, López Lomba expuso su versión de los acontecimientos de 1877. Recordaba su fervor como católico, su «amistad e intimidad» con monseñor Vera y su decidido apoyo a la fundación del Club Católico. Agregaba: «En cuanto me di por entero a los estudios filosóficos, mi catolicismo se vino al suelo, sobre todo después de estudiar a Descartes, que fue el autor que dio el último puntillazo a mis creencias religiosas». El Día, Montevideo, 13 de marzo de 1935, citado en Fernández Prando 1958: 33-35.

45 Fernández Cabrelli 1990: 320.

46 1889. Estatutos de la Liga Patriótica de Enseñanza: 3. 1889. Montevideo: Tipografía Americana a vapor.

47 1888. Manifiesto de la Liga Patriótica de Enseñanza a la población nacional y extranjera: 27. Montevideo: Tipografía Americana a vapor.

48 Camp sostenía que «en los principios del Derecho Natural» se fundamentaba «el derecho a la instrucción y el derecho del Estado para hacer obligatoria la enseñanza, en el estudio y la consideración de la misión del Poder público en las sociedades». Camp 1881: 9.

49 Ardao 1962: 235. pertenecían al mismo núcleo social y frecuentemente emparentaron por su matrimonio o el de sus hijos. ${ }^{50}$ Por otra parte, merecen especial atención dos destacados referentes intelectuales del Club, Juan Zorrilla de San Martín y Francisco Bauzá, en quienes nos detendremos más adelante.

Las relaciones establecidas y nutridas en el Club condujeron a la promoción de otras obras católicas, que conformaron una verdadera red institucional, muy próxima a la jerarquía pero animada por laicos casi siempre cercanos al centro católico que estudiamos. Desde el Club, se proyectó, en 1878, la fundación de El Bien Público, primer diario católico. Soler, Juan Zorrilla de San Martín, Eugenio Zoa O'Neill, Antonio J. Rius y Jacinto Casaravilla asumieron la gestión de la empresa y Zorrilla fue su director hasta 1885, cuando debió partir al exilio. ${ }^{51}$ También en el seno del Club maduró, en 1889, la idea de convocar el primer Congreso Católico Nacional; los integrantes de la Comisión del Congreso fueron todos socios del Club: Soler, Zorrilla, Carafí, Casaravilla, Bauzá, Hipólito Gallinal (h), Joaquín Requena, Carlos A. Berro y Francisco García y Santos. ${ }^{52}$

Por el contrario, el estudio de las redes que se conformaron en el Club Católico permite percibir que las mismas no implicaron la conformación de enlaces políticos en una sola dirección. En la sociedad católica convivieron blancos y colorados ${ }^{53}$, e integrantes de partidos menores y

50 ACCM, Club Católico de Montevideo. Matrícula de Socios. 18741893. Antonio J. Rius (fo3 y 197), Vicente Ponce de León (fo3), Hipólito Gallinal (h) (fo4), Jacinto Casaravilla (fo5 y 196), Eugenio Zoa O’Neill (fo6 y 196), Juan M. O’Neill (fo7). Vicente Ponce de León, hijo de Vicente Ponce de León Macuso y Eloísa Errazquin, hija de Joaquín Errazquin Larrañaga, estaba directamente emparentado con la familia Jackson, de fe católica y la más rica del país. Hipólito Gallinal, casado con Petrona Conlazo, fue el padre de Alejandro Gallinal, futuro esposo de Elena Heber Jackson, hija de Clara Jackson Errazquin y nieta de Clara Errazquin Larrañaga. Jacinto Casaravilla Vidal era primo de Jacinto D., Juan D., y Nicolás D. Durán Vidal, todos socios del Club. José D. Durán se casó con Beatriz Guani Peipoch, cuya hermana Antonia Guani Peipoch contrajo matrimonio con Héctor Pareja, también socio del Club. Nicolás D. Durán se casó con Rita Veiga Pareja; su hermana Clemencia Veiga Pareja lo hizo con Carlos Casaravilla Vidal, hermano de Jacinto; M. a Antonia Veiga Pareja se unió a Luis Pedro Lenguas, figura destacada del Club y del Círculo Católico de Obreros. Eugenio Zoa O'Neill y su hermano Juan Martín eran sobrinos de Nicolás Zoa Fernández, casado con Catalina O’Neill y antiguo socio de su padre. Eugenio Zoa O'Neill contrajo matrimonio con M. a Josefa Arocena Artagaveytia, hermana de Eduardo y Alejo Arocena, también socios del Club. Goldaracena 1976, Tomo 1: 124-127; 1978, Tomo II: 63-64, 1389, 191-192; 1981, Tomo III: 30-31.

51 Actas 9 de junio y 5 de noviembre de 1878. ACCM, Club Católico de Montevideo. Libro de Actas no 1. 1875-1883.

52 Actas 2 y 8 de febrero de 1889. ACCM, Club Católico de Montevideo. Asambleas Ordinarias y Extraordinarias. 1883-1923; Acta del 13 de febrero de 1889. ACCM, Club Católico de Montevideo. Libro de Actas no 3. 1887-1900.

53 El Partido Colorado «colorados» y el Partido Nacional «blancos» nacieron en 1836, seis años después de la independencia del Uruguay y son considerados los partidos tradicionales o históricos. En sus orígenes el Partido Colorado tuvo un perfil liberal y europeísta, que lo acercó a los unitarios argentinos; el Partido Nacional, también en sus inicios, fue un partido conservador y americanista, cercano a los federales de Juan Manuel de Rosas. En el correr del siglo XIX estos grupos políticos, nacidos como corrientes personalistas, definieron sus estructuras y sus programas. A comienzos del siglo $\mathrm{xx}$, el Partido Nacional era el partido reivindicador de las libertades políticas y las garantías del sufragio, mientras el Partido Colorado se definió como el promotor de las reformas económicas y sociales que le valieron el apoyo de las clases medias y los sectores obreros. 
de corta vida, como el partido Constitucional. Sin embargo se aprecia un mayor número de socios, de trayectoria destacada, militantes e incluso legisladores por el Partido Nacional (blanco): Jacinto Casaravilla, Jacinto D. Vidal, Hipólito Gallinal (h), Juan M. O’Neill, Vicente Ponce de León. Francisco Bauzá fue el único político colorado destacado en el seno del Club Católico, y por momentos fue resistido. ${ }^{54} \mathrm{En}$ concreto, la sociedad no operó en función de lazos políticos, pero ella se resintió ocasionalmente por los sucesos de la vida nacional.

Un último punto, que solo mencionaremos, se refiere al rol de las mujeres en la vida de la asociación y en el tipo de sociabilidad que su integración al Club contribuyó a desarrollar. Desde 1876, de manera mucho más firme desde 1878, Mariano Soler propuso el ingreso de las mujeres como "socias colaboradoras» del Club Católico y su vinculación con el desarrollo de veladas culturales. Este planteo generó un debate de interés y algunos socios pidieron restricciones a la actividad de las mujeres en la sociedad. Antonio J. Rius, si bien partidario del ingreso de las "socias colaboradoras", solicitó limitaciones a la participación femenina, dado que la reforma propuesta «daba a las socias atribuciones ilimitadas pues permitía que cualquiera de ellas pudiera presentar un trabajo lo que no armonizaba con el carácter y la naturaleza de la mujer». Soler manifestó mayor apertura, respondiendo «que poco importaba (...), pues las personas que se consideraran aptas podrían presentar trabajos relativos a los deberes de la mujer y otros muchos puntos que ellas podían abrazar $» .^{55}$ Seguramente, el director trataba de ampliar el alcance de las actividades de la sociedad y de atraer a las familias. En efecto, a partir de 1881 se organizaron mensualmente veladas "literario-musicales», lo que supuso un aumento muy significativo de socias colaboradoras y de socios suscriptores. Entre 1880 y 1882 el Club casi duplicó el número de socios y los triplicó ampliamente a fines de $1884 .{ }^{56}$ El desarrollo del perfil social, incluso recreativo, de la sociedad motivaría alguna inquietud, relacionada con el mantenimiento de su identidad filosófica. En ese sentido, el año 1884 marcó cambios en el Club; sería un año de reforma del Reglamento, de instalación en un nuevo local, de desarrollo de relaciones más regulares con los católicos argentinos y chilenos.

\section{POLÉMICAS FILOSÓFICAS Y RELIGIOSAS}

Las actitudes de resistencia y de oposición, ante posiciones filosóficas que desconocían o resistían la doctrina católica, fueron frecuentes por parte de los miembros del Club Católico. En esta línea se organizaron actividades académicas y sociales para formar a los socios más jóvenes, afirmar la identidad cristiana de las familias y atraer a los indecisos. Los dirigentes del Club oscilaron entre propuestas abiertas

54 Acta del 26 de julio de 1883. ACCM, Club Católico de Montevideo. Asambleas Ordinarias y Extraordinarias. 1883-1923.

55 Actas 9 de julio de 1978, 25 y 30 de abril de 1881. ACCM, Club Católico de Montevideo. Libro de Actas no 1. 1875-1883.

56 Los socios eran 91 a fines de 1875; 218 en 1880; 418 en 1882 y 742 en 1884 . Ascendían a 919 en 1890, hacia el fin del período estudiado. ACCM, Club Católico de Montevideo. Matrícula de Socios 18741893. Estas cifras implican cierto margen de imprecisión, porque no hay información sobre los socios que cancelaban su membrecía. -polémicas con racionalistas y positivistas, veladas con muy amplia participación, registro de socios no católicos, intentos de incluir a los "vacilantes», en expresión de Mariano Soler-y propuestas orientadas al crecimiento interior y a la reafirmación de la identidad católica -realización de sesiones privadas para socios activos, ciclos de conferencias de carácter interno, actos de testimonio público de fe católica.

Las polémicas que se desarrollaron en la sociedad católica merecen especial atención. La temática de los ciclos de conferencias organizados por el Club Católico respondía a las inquietudes intelectuales del momento y las réplicas eran esperables. Educación y religión, teorías sobre el origen de la Tierra, aspectos morales y religiosos del racionalismo: estas son algunas de las cuestiones que provocaron los más sonados debates. Por otra parte, debe señalarse que, a partir de la asonada del 10 de enero de 1875, que condujera al inicio del "gobierno provisorio»-o dictadura-del coronel Lorenzo Latorre en marzo de 1876, la coyuntura política marginó a la juventud de los debates políticos durante más de diez años. En las polémicas filosóficas, literarias y religiosas los jóvenes universitarios canalizaron sus energías y seguramente algunas frustraciones.

El 23 de marzo de 1876, la Junta Directiva del Club difundió una convocatoria elocuente, invitando a los católicos montevideanos a la reunión pública de la asociación. Se anunciaba que Mariano Soler disertaría sobre «Posibilidad y necesidad de la Revelación» y comentaba "sabemos que se prepara una discusión interesante entre algunos estudiantes racionalistas de nuestra Universidad y varios socios del Club Católico». ${ }^{57}$ Como se presumía, esta sesión derivó en una encendida polémica entre Soler y López Lomba, como portavoces del Club, y Prudencio Vázquez y Vega ${ }^{58}$ y Manuel B. Otero ${ }^{59}$, en representación del Ateneo del Uruguay. ${ }^{60}$

Nuevas confrontaciones tuvieron lugar en 1878, cuando Soler dio tres ciclos de conferencias entre mayo y noviembre: El «Génesis en sus relaciones con las ciencias» -siete conferencias; "El Darwinismo»-tres conferencias; «El Racionalismo» -seis conferencias. Los enfrentamientos fueron ásperos en mayo de 1878, en ocasión del primer ciclo. ${ }^{61}$ Mariano Soler y Manuel B. Otero se erigieron en portavoces de tesis contrapuestas y los ánimos se alteraron.

\footnotetext{
57 EMP, Montevideo, 23 de marzo de 1876.

58 Prudencio Vázquez y Vega (1853-1883) Nació en Cerro Largo y se instaló en Montevideo para realizar estudios en la Universidad Mayor, donde se transformó en referente para su generación. Fue socio del Club Universitario, Club Literario Platense, Club Fraternidad, Club Joven América, Sociedad Filo- Histórica y Sociedad de Estudios Preparatorios, participando de la fundación del Ateneo del Uruguay. En 1878 fundó el diario liberal La Razón, opositor al gobierno de Latorre. En 1881 se doctoró en Derecho y murió prematuramente a causa de tuberculosis pulmonar.

59 Manuel B. Otero (1857-1933) Joven ateneísta, doctor en Derecho por la Universidad Mayor, acompañó a Prudencio Vázquez y Vega en la fundación del diario La Razón, junto con Daniel Muñoz y Anacleto Dufort y Álvarez. Participó, en 1884, en la fundación de la Liga Liberal. Integró la masonería, habiendo sido iniciado en la logia "Asilo de la Virtud» de Montevideo. Fue diputado, senador, y ministro de Relaciones Exteriores del Uruguay.

60 Acta 19 y 26 de marzo de 1876. ACCM, Club Católico de Montevideo. Libro de Actas no 1. 1875-1883. Esta fue la sesión que provocó el conflicto ya comentado entre Isasa y varios socios del Club.

61 Sobre esta polémica: Glick 1999: 57-60.
} 
El 26 de mayo, durante la tercera sesión dedicada al tema, Zorrilla de San Martín manifestó «que tuvo un gran sentimiento al saber de los desórdenes habidos en la anterior reunión; que en cuestiones científicas no son los aplausos los que las deciden sino razones y esperaba que en lo sucesivo no tendrían lugar semejantes disturbios». El Dr. Gregorio Pérez argumentó en favor de Otero, atribuyendo lo ocurrido a «expansiones del momento». Resulta elocuente la respuesta de Zorrilla, quien planteó «que no habían sido meras expansiones, puesto que dado un caso ¿era acaso necesario que para vivir el Dr. Otero muriera el Dr. Soler?»" ${ }^{62}$ La polémica continuó con la "Refutación» de Otero en el Ateneo, a la que respondió Soler con dos nuevas conferencias. Cuatro meses más tarde, se desarrolló una nueva polémica entre Soler y los visitantes ateneístas, con motivo del ciclo sobre el Racionalismo. ${ }^{63}$ Estos enfrentamientos despertaban mucho interés en los círculos letrados. La prensa se hacía eco de las alternativas de los debates y las imprentas lanzaban las tesis al reducido pero inquieto mercado montevideano. ${ }^{64}$

Dos años más tarde, en 1880, se organizó un nuevo ciclo de Soler, con el objetivo de rebatir la antropología poligenista y las teorías de Flammarion acerca de la pluralidad de los mundos habitados. ${ }^{65}$ En 1882 Soler desarrollaría el último ciclo, al que seguiría un largo silencio, sobre «La Masonería y su relaciones con el Cristianismo». En esta ocasión pareció anunciarse una nueva polémica, que no prosperó. ${ }^{66}$ Recién en 1889, Soler retomaría la palabra en la tribuna del Club, desarrollando seis conferencias sobre "La Sociedad Moderna y el porvenir». ${ }^{67}$

En lo que se refiere a los expositores católicos, durante los dos primeros años de vida de la sociedad se hicieron serios esfuerzos por cumplir el "Plan de Tesis», presentado por Soler en julio del 75. Los socios, entre los que podemos citar a Horacio Tabares, Ramón López Lomba, Augusto Serralta, Jacinto Casaravilla, Luis Barattini, Faustino Lazo, Nicasio del Castillo68, presentaron tesis sobre temas filosóficos

${ }^{62}$ Acta 26 de mayo de 1876. ACCM, Club Católico de Montevideo. Libro de Actas no 1. 1875-1883.

63 Acta 15 y 29 se setiembre, 6 y 13 octubre de 1876. ACCM, Club Católico de Montevideo. Libro de Actas no 1. 1875-1883.

64 El Siglo (ES), periódico liberal, publicó la refutación de Otero, bajo el título «El Génesis y la Geología», y se refirió a la conferencia del Soler del 16 de junio, como "los rayos fulminantes del Vaticano». EMP respondió el 20 de junio, apoyando los argumentos de Soler. EMP, Montevideo, 20 de junio de 1878. Pocas semanas después, la Librería Nacional de Antonio Barreiro y Ramos ponía a la venta El Génesis y la Geología o refutación y defensa de la armonía del Génesis con las ciencias geológicas. Conferencias leídas en el Club Católico por el doctor don Mariano Soler y en el Ateneo del Uruguay por el doctor don Manuel B. Otero (Montevideo, Barreiro y Ramos, 162 pág.). La obra reunía las cuatro tesis de Soler, la «Refutación» de Otero, la «Contra-refutación» de Soler, la "Última palabra» de Otero publicada en ES el 22 de junio, y la última conferencia de Soler en respuesta a Otero, del 7 de julio.

65 Actas 25 de abril, 9 de mayo, 13 de junio, 4 de julio, 1o y 22 de agosto, 5 y 19 de setiembre, 21 de octubre de 1880. ACCM, Club Católico de Montevideo. Libro de Actas no $1.1875-1883$.

66 Actas 27 de mayo, 3 y 10 de junio, 1ㅇ, 8 y 15 de julio, 19 de agosto de 1882. Ibídem. Las actas del mes de junio se refieren al Dr. Feuer y al Sr. Vallejo como impugnadores de las tesis de Soler.

67 Actas 9, 14 y 23 de agosto, 5, 13 y 19 de setiembre de 1889. ACCM, Club Católico de Montevideo. Libro de Actas no 3. 1887-1900.

68 En 1875, Tabares disertó sobre «El Indiferentismo religioso»; López Lomba sobre «La Abolición de la esclavitud llevaba a cabo única e históricos, siempre en relación con el cristianismo y su influencia social. Los contendores racionalistas también acudieron al Club para escuchar y discutir las exposiciones de Tabares, López Lomba y Casaravilla. ${ }^{69}$ Sin embargo, a partir de 1877, la participación de los jóvenes se vería notoriamente limitada y Soler se transformaría en el expositor casi exclusivo. Por un lado, la amplia cultura y el espíritu de estudio de Soler debían atraer a socios y visitantes, y daban jerarquía a las actividades académicas del Club. Sin embargo, este rol preponderante constituía también un signo alarmante de pobreza intelectual. ${ }^{70}$ Efectivamente, cuando Soler estuvo ausente del país -sus viajes fueron largos y frecuentes entre mayo de 1885 y enero de 1889- la sociedad pasó por extensos períodos de eclipse. De todos modos, esta situación del Club Católico no era excepcional; el Ateneo del Uruguay vivió etapas similares. Las tribunas recobraban vida cuando un acontecimiento local o externo reanimaba los debates.

En cuanto a los contendores, los más decididos y pertinaces fueron los ya nombrados Prudencio Vázquez y Vega y Manuel B. Otero, a quienes acompañaban sus partidarios y amigos. ${ }^{71}$ Sin embargo, con cierta frecuencia, los adversarios del Club y particularmente de Mariano Soler, guardaron silencio ante sus conferencias, lo que podría interpretarse como señal de respeto o de indiferencia. En tal sentido, los antagonistas de la sociedad católica arguyeron reiteradamente que la actitud enérgica de Soler y su tendencia a defender las posiciones de la Iglesia -también la de Juan Zorrilla de San Martín- eran el resultado de haber realizado sus estudios universitarios en el extranjero. ${ }^{72}$

En relación con la temática de las polémicas y de las argumentaciones esgrimidas, resulta de interés explorar en las posibles lecturas de los defensores de las posturas católicas. Para la formación de los socios y para su eventual preparación para posibles debates, el Club Católico otorgó especial

y gloriosamente por la Iglesia»; Serralta sobre "La Existencia de Dios»; Luis Barattini sobre «La Espiritualidad del alma en sus relaciones con la Fisiología y la Frenología». En 1876, Lazo expuso sobre «La Iglesia y la libertad»; Casaravilla sobre "Ventajas de las Cruzadas» y López Lomba sobre "Las Causas del protestantismo» entre otro temas. ACCM, Club Católico de Montevideo. Libro de Actas no 1. 1875-1883.

69 Actas 24 de junio, 4 de julio y 25 de julio de 1875. Ibídem.

70 En 1875 se organizaron ocho conferencias, ninguna a cargo de Soler. En 1876 se organizaron doce conferencias, cuatro de Soler (33\%). En 1877 se organizaron quince conferencias, catorce de Soler (93\%). En 1878 se organizaron dieciocho conferencias, diecisiete de Soler (94\%). En 1880 se organizaron dieciséis conferencias, nueve de Soler (56\%). En 1882 se organizaron siete conferencias, todas de Soler (100\%). En 1889 se organizaron siete conferencias, seis de Soler (86\%). En 1879 y 1881, entre 1884 y 1888 no hubo conferencias en el Club. Se organizaron, en su lugar, frecuentes veladas literario-musicales que acentuaron el perfil de centro social del Club Católico. Ver: Monreal 1991: 307-334.

71 Actas 25 de marzo de 1876, 25 de marzo de 1877, 12, 19 y 26 de mayo de 1878, 15 y 29 de setiembre de 1878. ACCM, Club Católico de Montevideo. Libro de Actas no 1. 1875-1883.

72 «Los doctores Soler y Zorrilla son los protagonistas de la acción. Educados ambos fuera de su país, en centros eminentemente católicos, creyeron que podrían aquí implantar las ideas que bullían en sus juveniles cabezas. Juzgaron a los sacerdotes católicos de este país, como unos posmas, unos pobres hombres que no se animaban a sumir una actitud enérgica, sin ver que la práctica y los años les habían enseñado que el catolicismo no podía enseñorearse aquí a banderas desplegadas y que su actitud pacífica era la que les había granjeado el respeto y simpatía de que generalmente gozaban». "La evolución católica», La Razón, Montevideo, 28 de diciembre de 1878, cit. en Ardao 1971: 102 y 103. 
importancia, como los demás centros culturales de la época, al desarrollo de su Biblioteca. Al inaugurarse el Club y elegirse las autoridades interinas, se designó al primer bibliotecario y comenzaron a ingresar las donaciones de los socios. Por Reglamento, cada socio del Club debía donar a la Biblioteca una obra, de no menos de 300 páginas. El 11 de julio de 1875 ya se habían recibido 46 obras y dos meses más tarde ya se contaba con "115 volúmenes y varios folletos». ${ }^{73}$

En 1899 la Biblioteca del Club Católico contaba con 1490 títulos y 2716 volúmenes, y 59 revistas en español -publicadas en Uruguay, Argentina, Chile y España-, francés e inglés. ${ }^{74}$ Entre ellas se cuentan títulos muy representativos de las publicaciones católicas de la época: La Ciencia Cristiana, La Civiltà Cattolica, La Cruz, La Hormiga de Oro, La Estrella de Chile, La Revista Católica, La Science catholique, La Semana Religiosa, Revista Argentina, Revista Franciscana, Revista Popular, algunas de edición descontinuada. De acuerdo a la información previa disponible, de 1884, el Club solo recibía entonces trece revistas. Solo dos suscripciones se mantenían quince años más tarde: La Civiltà Cattolica y La Cruz, de neta definición católica romana, editadas en Roma y Sevilla. También seguían figurando en el catálogo El Correo de Ultramar y The Graphic. ${ }^{75}$ Es muy posible que, como en 1884, estas revistas, también otras, fueran aún donadas por los socios que las recibían como suscriptores. ${ }^{76}$

En la Biblioteca convivían los clásicos griegos y romanos, españoles y franceses, con escritores católicos más o menos contemporáneos. Los autores de obras sobre Religión, Filosofía y Derecho resultan los más reveladores. Junto a La Imitación de Cristo de Kempis, se hallan textos del padre Lacordaire, el conde de Montalembert, Le Play, también algunas Cartas de monseñor Dupanloup. Los neocatólicos españoles Balmes y Donoso Cortés, Ortí y Lara y Menéndez y Pelayo estaban ampliamente representados en obras de filosofía, teología e historia, y, como era de esperar, no faltaba El liberalismo es pecado de Sardá y Salvany. También estaban presentes los polemistas ultramontanos Jean Joseph Gaume y Jacques Crétineau-Joly, el jesuita Augustin Barruel, sobre todo a través de las traducciones al español de sus obras, editadas en Barcelona o Madrid. Finalmente, destacamos las obras del núcleo fundador de La Civiltá Cattólica, revista portavoz del neotomismo italiano, los jesuitas Carlo M. Curci, Luigi Taparelli, Matteo Liberatore. En la misma línea, son particularmente numerosas las obras del neotomista español Niceto Alonso Perujo.

También figuraban -y serían leídos seguramenteautores que representaban las corrientes filosóficas que la doctrina católica combatía, con el propósito de dar debidos fundamentos a las réplicas del Club. Entre los espiritualistas, se encuentran las obras clásicas de Victor Cousin, Jules

73 Actas 29 de junio y 19 de setiembre de 1875. ACCM, Club Católico de Montevideo. Libro de Actas $n$ ㅇ 1. 1875-1883. EMP publicaba periódicamente la lista de las obras que ingresaban a la Biblioteca del Club.

74 En el catálogo los libros se presentaban divididos en doce secciones, siendo las más ricas: Literatura (275 títulos), Religión e Historia religiosa (269), Derecho y ciencias sociales (142) e Historia (137). 1899. Reglamento y catálogo de la Biblioteca del Club Católico. Montevideo: Tipografía Uruguaya de Marcos Martínez.

75 Ídem: 54 y 55; Acta 22 de mayo 1884, ACCM, Club Católico de Montevideo. Libro de Actas no 2. 1884-1887.

76 En este caso, Juan M. O'Neill y Alfonso Guillemette. Acta 5 de junio 1884, ibídem.
Simon y Paul Janet, autores de influencia determinante en la cátedra de Filosofía de la Universidad Mayor. No faltaban los krausistas, renovadores de las ideas espiritualistas ante el ingreso del positivismo, el alemán Enrique Ahrens y el belga Guillermo Tiberghien. En menor número se hallaban también algunas obras de los positivistas Stuart Mill y Darwin, del frenólogo Mariano Cubí y Soler y del astrónomo espiritista Camilo Flammarion.

\section{CATOLICISMO, CIVILIZACIÓN Y PATRIA}

En relación con el discurso más representativo del Club Católico, dos temas revisten especial interés: el énfasis en la relación, presentada como irrefutable, entre civilización y cristianismo, y la estrecha relación del Club con la definición de la identidad nacional.

Desde su discurso inaugural, Mariano Soler argumentó en favor de la "grande obra de regeneración religiosa y social» que correspondía a la sociedad y que se fundaba en la alianza entre Iglesia y civilización. En su opinión, la religión cristiana era y había sido creadora de civilización y su pérdida de influencia conllevaría la corrupción y la barbarie. Esta idea-fuerza en los textos de Soler $-y$ de sus seguidores- predominante en el pensamiento católico del siglo XIX, rechazaba las propuestas iluministas, y supuestamente anticristianas, que inspiraban a las nuevas filosofías espiritualistas y al liberalismo político.

En esta misma línea de pensamiento, en 1844, el salteño, ferviente católico, Félix Frías había publicado, en Valparaíso, la obra El cristianismo considerado como elemento de civilización de las repúblicas hispanoamericanas, en defensa de los fundamentos cristianos sobre los que debían construirse las nuevas repúblicas. Corresponsal de El Mercurio de Chile en Europa, entre 1848 y 1852, Frías no vivió la caída de Juan Manuel de Rosas en Buenos Aires y sí fue testigo de la revolución de 1848 en París. En estas circunstancias, la estadía en Europa consolidó su aprecio por el orden, como condición imprescindible del desarrollo social armónico; también fomentó sus relaciones con la tradición hispánica y con las publicaciones del llamado neocatolicismo, particularmente las obras más recientes de Jaime Balmes y Juan Donoso Cortés. Para Frías, el protagonismo de la Iglesia católica y el fortalecimiento de la religiosidad de las masas populares eran fundamentales para la construcción de las naciones hispanoamericanas. La nación debía construirse sobre el concepto de "civilización» que incluía organización política y social, progreso económico y civilidad; para algunos ella implicaba desarrollo de la educación pública, para otros afirmación de los valores religiosos y de las tradiciones cristianas. ${ }^{77}$ Tanto en la biblioteca personal de Mariano Soler, como en las bibliotecas del clero de Montevideo y del Club Católico se hallaban numerosas obras de Balmes, de Donoso Cortés y del propio Frías. ${ }^{78}$

77 Ver Pinto y Mallimaci 2013: 55-58; Halperín Donghi 1980: XXVI-XXVIII.

78 ACM, Inventario de las obras que formaban la Biblioteca de Mons. Mariano Soler para el juzgado. Versión manuscrita del Dr. Jacinto Casaravilla. Montevideo, 1909; ACM; Biblioteca del Clero para el uso de sus ministros. Índice General, Montevideo, 1881-1945; Club Católico de Montevideo. 1899. Reglamento y catálogo de la Biblioteca del Club Católico. Montevideo: Tipografía Uruguaya de Marcos Martínez. 
La estrecha asociación entre catolicismo y civilización fue esgrimida por Mariano Soler y sus discípulos de manera constante. Ya en los primeros meses de 1875 , varias veladas de la Sociedad Religiosa fueron dedicadas a la lectura de El protestantismo comparado con el catolicismo en sus relaciones con la civilización europea de Balmes; en 1877 Soler consagró un ciclo de conferencias al tema «Necesidad del principio religioso en la educación», consagrando atención especial a «la influencia de la religión en los destinos de la civilización y progreso de los pueblos»; en 1882 retomaría el tema en un ciclo sobre la masonería en sus relaciones con el cristianismo y la civilización. Muchas de estas conferencias fueron publicadas bajo la forma de folletos o libros; otras dieron lugar a obras más elaboradas y publicadas más tarde. En 1880 vio la luz Ensayo de paralelo entre el Catolicismo y el Protestantismo. Bajo el aspecto filosófico, religioso, político y social en sus relaciones con la civilización, el progreso y bienestar de los pueblos, que mantuvo la estructura original del ciclo de $1877 .{ }^{79}$ Cinco años más tarde, Soler publicaría su ciclo sobre la masonería, transformado en una obra de mayor enjundia. ${ }^{80}$

En cualquier caso, el mensaje era inmutable: se reafirmaba la influencia civilizadora de la Iglesia católica a lo largo de toda la historia de Occidente, y no existía oposición posible entre la sociedad moderna y el catolicismo: «Para el Catolicismo el deber fundamental del individuo y de la sociedad es el deber de civilizarse, como quiera que civilización consiste en el perfeccionamiento armónico y progresivo de las facultades físicas, morales e intelectuales del hombre, ya que ese es nuestro fin y el precepto esencial de Jesucristo». ${ }^{81}$ Cualquier antagonismo solo podía explicarse por el desconocimiento de los valores cristianos; en estos casos cabía al cristianismo ser fuerza de regeneración y curación. «Por eso el cristianismo apareció en el mundo como un gigante colosal y basado en la unidad de su código moral y religioso, el Evangelio, acabó con la disolución moral y religiosa [...]; y del caos informe del paganismo y de la barbarie, legó al mundo la gloria de la civilización moderna, porque sin la unidad de principios fijos en moral y religión no hay civilización». ${ }^{82}$ Dos años antes de su muerte, en 1906, en un contexto de fuerte anticlericalismo, Soler todavía publicó una carta pastoral sobre el tema y en la misma línea: «En efecto, la era cristiana es la era de la civilización y progreso de los pueblos; ya que desde que se extendió la religión de Jesucristo empezó a renovarse el mundo». ${ }^{83}$

En los trabajos del Club Católico, también el concepto de "patria» se vinculó estrechamente con la fe y con los principios cristianos. En momentos en que el sentimiento nacional se consolidaba en las repúblicas hispanoamericanas, el Club Católico representó un espacio en cuyo seno se asociaron los conceptos de patria y cristianismo. Sin embargo, no fueron las actividades académicas sino las veladas sociales, de carácter familiar, las que marcaron la agenda en

\footnotetext{
79 Soler 1880: 188.

80 Soler 1885. Católicos y Masones. La masonería y el catolicismo. Estudio comparado bajo el aspecto del derecho común, las instituciones democráticas y filantrópicas, la civilización y su influencia social. Montevideo: Imprenta de Rius y Bechi 382 pág.

81 Soler 1879

82 Soler 1885: 76

83 Soler 1905.
}

tal sentido. Si bien desde julio de 1876 se realizaron certámenes literarios con numerosa concurrencia, la década de 1880 traería novedades. Citamos, como ejemplo, el Certamen Literario «en memoria de los Treinta y Tres Orientales», del 19 de abril de $1881 .{ }^{84} \mathrm{Al}$ discurso «La obra de los 33» de Augusto Serralta siguieron los poemas «Saludo de Lavalleja a la Patria» y "Nuestra bandera», y los discursos "El patriotismo» y "Trenos». La prensa montevideana se hizo eco de la velada y se multiplicaron los elogios al discurso de Mariano Soler, «Trenos». ${ }^{85}$

Por otra parte, Juan Zorrilla de San Martín y Francisco Bauzá de rol muy significativo en la definición de la identidad uruguaya, recibieron del Club amplio apoyo institucional. Terminados sus estudios de Derecho en Chile, Juan Zorrilla de San Martín regresó a Montevideo y se integró a la vida del Club, en enero de 1878. Fue presidente de la sociedad y el primer director de El Bien Público, el diario católico fundado desde el Club. ${ }^{86}$ Zorrilla adquirió dimensión de figura nacional, a partir de mayo de 1879, cuando luego de declamar La Leyenda Patria, se convirtió en «el poeta de la Patria». Desde 1883, en veladas del Club Católico, Zorrilla leyó por primera vez en público varios pasajes del poema Tabaré, su obra consagratoria. El Tabaré, la «epopeya nacional» uruguaya al decir de Anatole France, fue publicado en Montevideo en 1888. Mestizo de ojos azules, hijo de cacique indio y madre española, Tabaré se transformó en símbolo nacional. El poema sería elogiado por autores europeos e hispanoamericanos y Zorrilla fue designado, en 1885, académico correspondiente de la Real Academia Española. ${ }^{87}$

En cuanto a Francisco Bauzá, si bien ingresó tardíamente y no ocupó cargos directivos en la sociedad, sus aportes fueron decisivos en las obras de carácter social y pedagógico promovidas por la asociación: la Universidad Libre o Católica de la que fue el único rector laico, el Instituto Pedagógico que dirigió, el Círculo Católico de Obreros del que fue primer presidente en 1885. En 1881, Bauzá publicó su Historia de la dominación española en el Uruguay, obra que contribuiría decisivamente a la construcción de la identidad uruguaya, transformando a su autor en el primer historiador nacional. ${ }^{88}$ El historiador «de la Patria» publicó también varias obras de carácter didáctico, utilizadas como manual en las escuelas católicas y en otras escuelas del país. Francisco Bauzá publicó Deberes y Derechos del Ciudadano, y Compendio Historial del Uruguay en octubre de 1885, y Nociones de Geografía Uruguaya en 1886. El Compendio Historial del Uruguay, para niños en edad escolar, revelaba el afán de Bauzá por fortalecer los fundamentos de la nación, a través de la elaboración y la comunicación de un

84 EBP, Montevideo, 21 de abril de 1881. Los «Treinta Tres Orientales», liderados por Juan Antonio Lavalleja, fueron los míticos iniciadores de la revolución de 1825 que culminaría con el fin del dominio brasileño y la independencia del Uruguay.

85 «Honrar la patria», $E B P$, Montevideo, 21 de abril de 1881 y «Más sobre el Club Católico», EBP, Montevideo, 22 de abril de 1881. El último artículo transcribía comentarios de otros diarios.

86 Actas 25 de julio de 1875, 17 de marzo y 27 de octubre de 1878. ACCM, Club Católico de Montevideo. Libro de Actas no 1. 1875- 1883 y Club Católico de Montevideo. Matrícula de Socios. 1874-1893.

87 EBP, Montevideo, 1으 de julio y 17 de agosto de 1883.

88 Ver González Laurino 2001. 
relato histórico que le diera sentido. ${ }^{89}$ Se refiere a la Historia de la República del Uruguay, como una «Historia particular» que «narra solamente la historia del pueblo uruguayo». ${ }^{90}$ En esa línea, alude a los "indígenas uruguayos» y a los «indígenas argentinos» que enfrentaron a los soldados de Pedro de Mendoza; a los españoles, jesuitas y portugueses que "conquistaron el territorio uruguayo»; al tratado de Madrid como «un hecho que por sí solo puso en peligro la existencia del Uruguay y todavía produce sus efectos en la marcha política de la Nación ». ${ }^{91}$

Promotores de la conciencia comunitaria nacional, Bauzá y Zorrilla cumplieron esta función como católicos comprometidos y desde la tribuna del Club.

\section{A MODO DE CIERRE}

A lo largo de dos décadas, la actividad cultural, la polémica como constante y el indiscutido perfil católico y romano caracterizaron la acción del Club Católico. Ante el perfil racionalista, primero, y positivista más tarde de las sociedades de estudiantes, el Club se definió como espacio de sociabilidad para quienes compartían la fe cristiana y la identidad católica.

Puesto que esta sociedad católica fue fundada como "centro científico-religioso», orientado a la «regeneración religiosa y la regeneración social» de la juventud estudiosa, parecía imprescindible estudiar las verdades de la ciencia y develar sus relaciones con las verdades de la fe. Precisamente, cuando el Club reinició sus sesiones públicas en 1876, Mariano Soler pronunció un discurso titulado «Influencia del catolicismo en la ilustración y progreso científico $» .^{92}$ Las actividades culturales primaron en la sociedad entre 1875 y 1882, y, si bien su ritmo decreció con los años, no desaparecieron nunca por completo.

Por otra parte, la sociedad también se consolidó como centro social de la burguesía católica, montevideana preferentemente. Ya hemos señalado que, en 1886, el obispo Yéregui destacaba que el Club había sido fundado para "congregar todo el elemento no obrero» y que Soler afirmaba, en 1896, que "es el centro donde se congrega todo lo más culto y distinguido de nuestra sociedad». En la misma línea, las crónicas de las veladas culturales del Club se refieren a "l'élite de nuestra sociedad», a "las damas que forman la clase alta de nuestra sociedad», a "las familias más notables y de mayor influencia en el país». ${ }^{93}$ Por otra parte, no faltaron ataques desde la prensa representante de sectores inmigrantes que acusaba al Club de estar cerrado a los católicos «pobres y honrados». La respuesta fue enérgica y la sociedad afirmaba no estar cerrada «a quiénes respetan las tradiciones y el carácter nacional». ${ }^{94}$

Resulta de interés el espacio que ocuparon los temas científicos en las actividades académicas del Club,

89 Ver Monreal 2002.

90 Bauzá 1889: 5.

91 Ibídem: 16, 17 y 30.

92 Acta 5 de marzo de 1876. ACCM, Club Católico de Montevideo. Libro de Actas no 1. 1875-1883; Soler 1877.: 53-70. Montevideo: Tipografía de El Mensajero del Pueblo.

93 El Bien Público (EBP), Montevideo, 21 de abril y 22 de julio de 1881.

${ }^{94}$ EBP, Montevideo, 25 de septiembre de 1884. motivando interesantes polémicas. Si bien se trata de un tema a retomar en estudios futuros, corresponde señalar que su análisis permitiría abrir nuevas perspectivas sobre las relaciones entre ciencia y religión, en la región, a partir de las últimas décadas del siglo XIX. ${ }^{95}$

En contexto de secularización, de redefinición del perfil de la Iglesia católica en el continente americano, el Club Católico, que nació y se desarrolló enmarcado por el "Nuevo Catolicismo», potenció formas de sociabilidad que implicaban apuestas de futuro. Por un lado, su accionar se centró en los jóvenes -«El cristianismo y la juventud (...) han sido siempre el áncora de salvación y la esperanza suprema de las naciones abatidas y agotadas $\gg-.{ }^{96}$ Por otro lado, aun cuando la personalidad de Soler resultó por momentos omnipresente, los actores constantes y discretos de la vida del Club fueron los laicos; el «laicado católico», la «sociedad civil» constituían la "gran esperanza de los tiempos actuales $" .^{97}$ En los hechos, estas apuestas no dieron, con frecuencia, los resultados esperados.

\section{FUENTES}

Club Católico de Montevideo. 1875. Estatutos del Club Católico Central de Montevideo inaugurado el 24 de junio de 1875. Montevideo: Tipografía de El Mensajero del Pueblo.

Club Católico de Montevideo. 1899. Reglamento y catálogo de la Biblioteca del Club Católico. Montevideo: Tipografía Uruguaya de Marcos Martínez.

Liga Patriótica de Enseñanza. 1889. Estatutos de la Liga Patriótica de Enseñanza. Montevideo: Tipografía Americana a vapor.

Manifiesto de la Liga Patriótica de Enseñanza a la población nacional y extranjera. 1888. Montevideo: Tipografía Americana a vapor.

Sociedad de Ex alumnos del Colegio-Liceo de la Inmaculada Concepción. 1940. Breve historia del Colegio. Montevideo: s. e.

Una historia nos impulsa. 125 años de presencia salesiana en Uruguay. 2001. Montevideo: El País.

\section{BiBLIOGRAFÍA}

Acevedo, E. 1934. Anales históricos del Uruguay. Montevideo: Barreiro y Ramos.

Ardao, A. 1962. Racionalismo y liberalismo en el Uruguay. Montevideo: Universidad de la República.

Ardao, A. 1971. "Las ideologías en la iniciación de Zorrilla de San Martín», en A. Ardao, Etapas de la inteligencia uruguaya: 93-111. Montevideo: Universidad de la República.

Barbieri, A. M. a 1933. Los capuchinos genoveses en el Río de la Plata: apuntes históricos. Montevideo: Urta y Curbelo.

Bauzá, Fco. 1889. Compendio Historial del Uruguay. Montevideo: Tipografía Uruguaya.

95 Sobre relaciones entre ciencia y religión, en el Río de la Plata: De Asúa, M. 2010. Una gloria silenciosa. Dos siglos de ciencia en Argentina. Buenos Aires: Zorzal, y 2010. De cara a Darwin. La teoría de la evolución y el cristianismo. Buenos Aires: Lumen; Castelfranco, Diego. 2014. «La Voz de la Iglesia y el discurso católico sobre la ciencia en la Argentina de fines del siglo XIX (1885-1895), Itinerantes. Revista de Historia y Religión. 4: 135-161.

96 Soler «La Actualidad», EBP, Montevideo, 1ㅇ de agosto de 1879.

97 Carta de M. Soler a J. Casaravilla, Roma, 2 de noviembre de 1888, El Bien Público, Montevideo, 24 de enero de 1946. ACEM. Mons. Soler. Carpeta no 6: Centenario del nacimiento (1946). 50 aniversario de la muerte (1958). 
Bruno, P. 2009. «La vida letrada porteña entre 1860 y el fin-de-siglo. Coordenadas para un mapa de la élite intelectual». Anuario IEHS, 24: 338-369.

Bruno, P. 2014. «Introducción. Sociabilidad y vida cultural en Buenos Aires, 1860-1930», en P. Bruno (dir.), Sociabilidades y vida cultural. Buenos Aires, 1860-1930: 9-26. Bernal: Universidad Nacional de Quilmes.

Camp, S. A. 1881. Breves consideraciones sobre la enseñanza obligatoria. Tesis para optar al grado de Doctor en Jurisprudencia. Montevideo: Tipografía "La España».

Clark, Ch. 2003. "The New Catholicism and the European culture wars» en Ch. Clark y W. Kaiser (ed.), Culture Wars: SecularCatholic Conflict in Nineteenth-Century Europe: 11-46 Cambridge: Cambridge University Press.

Clark, Ch. y Kaiser, W. 2003. Culture Wars: Secular-Catholic Conflict in Nineteenth-Century Europe. Cambridge: Cambridge University Press.

Di Stefano, R. 2010. «Pensar la Iglesia: el Río de la Plata entre la reforma y la romanización (1820-1834)». Anuario de Historia de la Iglesia, 19: 221-239.

Di Stefano, R. 2010. «¿De qué hablamos cuando decimos 'Iglesia'? Reflexiones sobre el uso historiográfico de un términos polisémico». Ariadna histórica. Lenguajes, conceptos, metáforas. 1: 197-222.

Fernández Cabrelli, A. 1990. Iglesia ultramontana y masonería en la transformación de la sociedad oriental. Montevideo: América Una.

Fernández Prando, F. 1958. Escritos y discursos de Prudencio Vázquez y Vega. 1875-1882. Montevideo: Atenas.

Glick, T. F. 1999. "La recepción del darwinismo en Uruguay» en Th. F. Glick, R. Ruiz, y M. A. Puig-Samper (ed.), El darwinismo en España e lberoamérica: 47-67 Madrid: CSIC.

Goldaracena, R. 1976. El libro de los linajes. Tomo I. Montevideo: Arca. Goldaracena, R. 1978. El libro de los linajes. Tomo II. Montevideo: Arca.

Goldaracena, R. 1981. El libro de los linajes. Tomo III. Montevideo: Arca.

González Laurino, C. 2001. La construcción de la identidad uruguaya: 105-148 y 207-227. Montevideo: Taurus-UCU.

Halperín Donghi, T. 1980. «Prólogo. Una nación para el desierto argentino» en T. Halperín Donghi (comp.), Proyecto y construcción de una nación: Argentina, 1846-1880: XI-Cl. Caracas: Biblioteca Ayacucho.

Molina, E. 2011. "Sociabilidad y redes político-intelectuales: Algunos casos entre 1800 y 1852». Cuadernos del CILHA, 12 (14): 19-53.

Monreal, S. 1991. «El Club Católico de Montevideo (1875-1890). Presencia de Mariano Soler», en M.a del R. Griego y otros, Monseñor Soler. Acción y obras: 241-370. Montevideo: Hegil.

Monreal, S. 2002. «Francisco Bauzá. Su docencia a través de la Historia», Revista del Instituto Histórico y Geográfico, 28: 59-80.
Monreal, S. 2005. «Las propuestas educativas francesas en Uruguay en el siglo XIX. Las congregaciones católicas francesas», Prisma, 20: 49-98.

Paris de Oddone, M. a B. 1958. La Universidad de Montevideo en la formación de nuestra conciencia liberal. Montevideo: Universidad de la República.

Pinto, J. y Mallimaci F. 2013. La influencia de las religiones en el Estado y la Nación Argentina. Buenos Aires: Eudeba.

Piñeyro Gutiérrez, A. 2009. Luis Piñeyro del Campo. Caridad y dignidad. Montevideo: Artemisa.

Pollero, R. 1988. "Clubes y sociedades científico-literarias en el Uruguay (1868-1886)», en Prudencio Vázquez y Vega. Estudios, selección de escritos y discursos: 53-65. Montevideo: Blanes.

Pou Ferrari, R. y Mañé Garzón, F. 2013. José Máximo Carafí 1853-1895: primer decano uruguayo y organizador de la nueva Facultad de Medicina de Montevideo. Montevideo: Plus Ultra.

Roux, R. R. de. 2014. "La romanización de la Iglesia católica en América Latina: una estrategia de larga duración». Pro-Posições. 25/1: 31-54.

Sábato, H. 2008. «Nuevos espacios de formación y actuación intelectual prensa, asociaciones, esfera pública (1850-1900)», en C. Altamirano (dir.) y J. Myers (ed.), Historia de los intelectuales en América latina, vol. 1: 387-411. Buenos Aires: Katz Editores.

Santirocchi, I. D. 2010. «Uma questão de revisão de conceitos: Romanização. Ultramontanismo. Reforma». Temporalidades. 2/2: 24-33.

Soler, M. 1877. Ensayos de una pluma. Artículos y discursos. Montevideo: Tipografía de «El Mensajero del Pueblo».

Soler, M. 1879. La gran cuestión en páginas de la Historia. Montevideo: Tipografía de «El Bien Público».

Soler, M. 1880. Ensayo de paralelo entre el Catolicismo y el Protestantismo. Bajo el aspecto filosófico, religioso, político y social en sus relaciones con la civilización, el progreso y bienestar de los pueblos. Montevideo: Tipografía de «El Bien Público».

Soler, M. 1885. Católicos y Masones. La masonería y el catolicismo. Estudio comparado bajo el aspecto del derecho común, las instituciones democráticas y filantrópicas, la civilización y su influencia social. Montevideo: Imprenta de Rius y Bechi.

Soler, M. 1905. La Iglesia y la Civilización. Pastoral. Montevideo: Tipografía Uruguaya de M. Martínez.

Villegas, J. 1989. La Carta Pastoral de Monseñor Jacinto Vera acerca de la Profesión de Fe Racionalista en su entorno. Montevideo: Pesce Hnos.

Wilson, E. 1992. "Jacinto de León: primer neurólogo uruguayo", Revista Médica del Uruguay, 8 (2): 75-88. Disponible en: www. rmu.org.uy/revista/8/2/2/es/1/

Zorrilla de San Martín, C. 1970. Momentos familiares. Montevideo: Bouzout.

Zorrilla de San Martín, J. 1965. Conferencias y discursos. Montevideo: Barreiro y Ramos. 